\title{
Reaching new dimensions: the 49th Annual AMI Conference
}

The annual conference of the Association of Microbiologists of India (AMI) is a key feature to promote research in microbiology and facilitate close interaction between microbiologists and scientists from other allied disciplines. This year's conference, jointly organized by the Department of Zoology and Department of Microbiology, University of Delhi, has been the largest international gathering of microbial community in India boasting of attendance by 1200 delegates from India and other parts of the world. The conference centered on the theme "Microbial Biotechnology: Diversity, Genomics and Metagenomics" and was a highly informative and interactive programme. Apart from a plenary lecture by Dr. Avedhesha Surolia, there were 65 invited lectures covering diverse areas of microbiology and keynote presentations by several eminent speakers who included some of their most outstanding work. These led to extensive open, productive and stimulating deliberations between the audience and speakers. There were nearly 700 poster presentations to promote our upcoming talent. While the invited lectures highlighted recent trends in several areas of microbiology and allied disciplines, poster presentations displayed high quality of research that is being pursued in India. This has been in tune with AMI's ideology to promote scientific exchange between microbiologists of different expertise and provide opportunities for young microbiologists. The sessions on "Metagenomics, Genomics and Proteomics" and "Bioinformatics" brought into attention the areas where more funding is required to provide impetus to research initiatives specifically in these areas in our country. The session on "Microbial Secondary Metabolite Biosynthesis" included internationally renowned speakers and their presentations enlightened the audience to this exciting field, the potential of which still needs to be explored in our country.
One highlight of this year's conference is the commencement of ties between AMI-ASM (American Society for Microbiologists). ASM is world's largest scientific society devoted to microbiological sciences. To formalize this, a special session entitled "Food- and Water-Borne Pathogens" was organized in association with ASM President Prof. Alison O'Brien, a renowned scientist and highly cited researcher Prof. James Kaper and ASM Manager for International Affairs Todd Peterson. A delegation from another world-class microbiology organization, ISME (International Society of Microbial Ecology) comprising its President, Prof. Hillary Lappin Scott and ISME-12 Chairperson and Organizing Secretary, Prof. Linda Blackall, was present to participate in the conference. Arrangements were made to put up AMI-ASM and ISME stalls to provide information to the youngsters about AMI and these two renowned organizations. Participation by ASM and ISME teams is a boost to AMI's international recognition and it is hoped that in future AMI-ASM and AMI-ISME cooperation would grow further and set new milestones.

Many participants brought excellent posters which were also the focus of much informative discussions. I am delighted to see enthusiastic involvement and overwhelming response by the attendees. There were awards, such as the Young Scientist Award, in addition to several poster awards which were distributed to young students. Many scientists, students and invited speakers appreciated the way this conference was organized. I hope that the success achieved this year accelerates in forthcoming years, reaching newer dimensions and accomplishing higher standards.

Editor-in-Chief Prof. Rup Lal 